EUROPEAN CENTRAL BANK

WORKING PAPER SERIES

N0. 365 / MAY 2004

\title{
EXCHANGE RATES AND FUNDAMENTALS
}

NEW EVIDENCE FROM REAL-TIME DATA

by Michael Ehrmann and Marcel Fratzscher

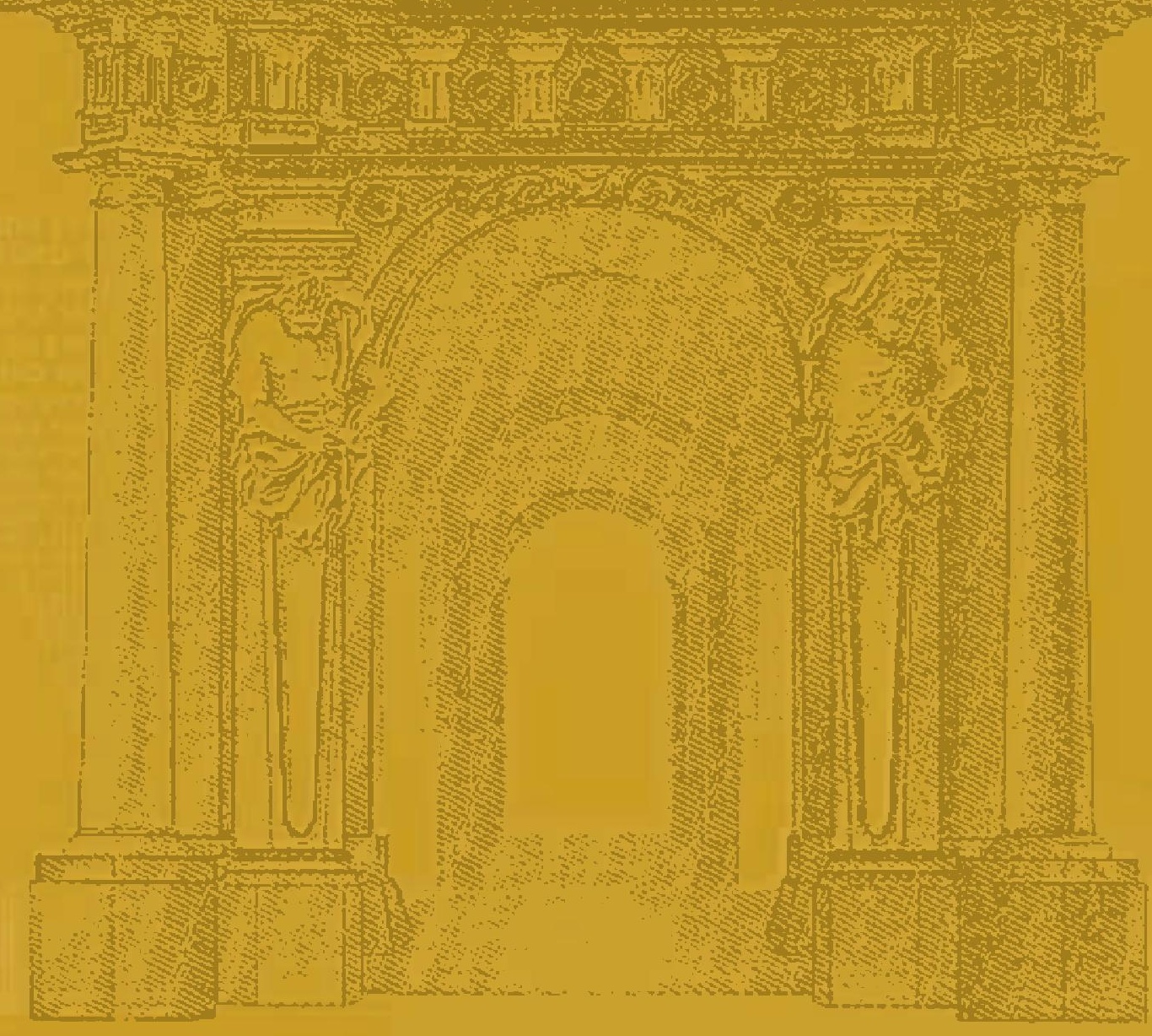


EUROPEAN CENTRAL BANK

\title{
WORKING PAPER SERIES
}

N0. 365 / MAY 2004

\author{
EXCHANGE RATES \\ AND FUNDAMENTALS \\ NEW EVIDENCE FROM \\ REAL-TIME DATA'
}

by Michael Ehrmann and

Marcel Fratzscher ${ }^{2}$

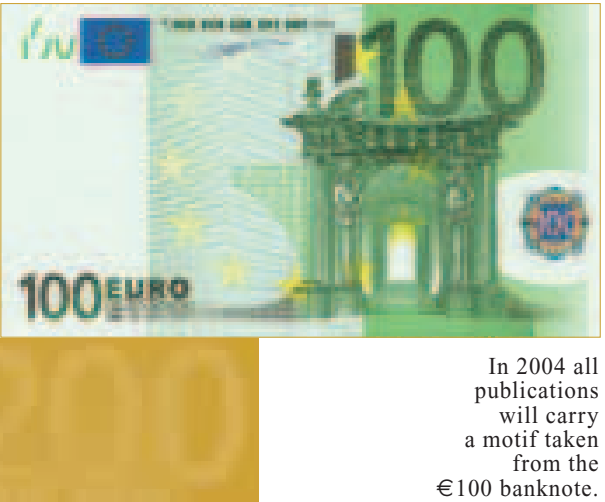

This paper can be downloaded without charge from http://www.ecb.int or from the Social Science Research Network electronic library at http://ssrn.com/abstract_id $=533124$. 


\section{(C) European Central Bank, 2004}

\section{Address}

Kaiserstrasse 29

60311 Frankfurt am Main, Germany

Postal address

Postfach 160319

60066 Frankfurt am Main, Germany

Telephone

+496913440

\section{Internet}

http://www.ecb.int

Fax

+496913446000

Telex

$411144 \mathrm{ecb} d$

All rights reserved.

Reproduction for educational and noncommercial purposes is permitted provided that the source is acknowledged.

The views expressed in this paper do not necessarily reflect those of the European Central Bank.

The statement of purpose for the ECB Working Paper Series is available from the ECB website, http://www.ecb.int.

ISSN 1561-0810 (print)

ISSN 1725-2806(online) 


\section{CONTENTS}

Abstract

Non-technical summary 5

1. Introduction 7

2. Exchange rates, fundamentals and news: the data 9

2.1 Fundamentals and news: the case for using real-time data

2.2 Exchange rates and frequency issues

2.3 Extracting market news about economic fundamentals

3. Exchange rate responses to news: the econometric model

4. How important are fundamentals? Empirical results for linear models

4.1 Exchange rate responses to news reflecting the real economy

4.2 Exchange rate responses to monetary policy shocks

4.3 Exchange rate responses to news about price developments

4.4 How important is the announcement timing?

4.5 Exchange rate responses to composite indicators of macroeconomic news

5. Asymmetries in exchange rate responses to news of fundamentals

5.1 Size effects and sign effects of news

5.2 The importance of uncertainty

6. Evaluating the real-time model of fundamentals and exchange rates

7. Conclusions

References

Appendix

European Central Bank working paper series 


\begin{abstract}
This paper analyses the link between economic fundamentals and exchange rates by investigating the importance of real-time data. We find that such economic news in the United States, Germany and the euro area have indeed been a driving force behind daily US dollar - euro/DEM exchange rate developments in the period 1993-2003. The larger importance of US macroeconomic news is at least partly explained by their earlier release time compared to corresponding German and euro area news. The exchange rate is also shown to respond more strongly to news in periods of large market uncertainty and when negative or large shocks occur. Overall, the model based on real-time data is capable of explaining about $75 \%$ of the monthly directional changes of the US dollar-euro exchange rate, although it does not explain well the magnitude of the exchange rate changes.
\end{abstract}

JEL classification: F31, F42, E52.

Keywords: exchange rates; fundamentals; announcements; news; real-time data; United States; euro area; interdependence; US dollar euro; EMU. 


\section{Non-technical summary}

20 years after the influential paper by Meese and Rogoff (1983), only modest progress has been made in explaining and predicting exchange rate movements with macroeconomic fundamentals. In particular, econometric attempts to explain shortand medium-term movements in exchange rates have had limited success so far.

This paper takes a different and relatively novel approach to analysing the link between fundamentals and exchange rate movements. We argue that a potentially important shortcoming of standard, fundamentals-based models of the exchange rate is that they use measures of fundamentals that do not accurately reflect the true information market participants have when making trading decisions. In this paper, we test for the role and importance of real-time data, i.e. data about daily announcements of relevant macroeconomic and monetary policy variables as they become available to financial markets.

The paper attempts to contribute to the literature in two central ways. First, the paper focuses on the presence of asymmetries in the reaction of exchange rates, and in particular on the question whether existing market conditions are an important determinant for explaining why the conditional means of exchange rates react differently to macroeconomics news over time. And second, the paper provides an evaluation of the overall importance of macro news on exchange rates. This second issue is of large relevance because from a policy perspective, news about economic fundamentals are important for overall exchange rate movements only if these effects are sufficiently long-lived in that they drive exchange rate developments on a daily or monthly frequency.

Looking at a broad set of the most important macroeconomic and monetary policy news in the United States and the euro area/Germany for the period 1993-2003, we find that, first, news about fundamentals can explain relatively well the direction in recent years, but only to a much smaller extent the magnitude of daily and monthly exchange rate developments. We show that the exchange rate model using real-time data outperforms strongly the same exchange rate model using vintage data. The model using real-time data correctly explains $73 \%$ of the directional changes of 
monthly exchange rates, whereas the model using vintage data only correctly accounts for $60 \%$ of the directional changes.

Second, we find that news about the US economy have a larger impact on exchange rate movements than news emanating from the euro area. We show that this may reflect at least in part the fact that US announcements are usually released earlier than comparable euro area or German announcements. Third, the effects of news on exchange rates are found to be asymmetric in that they depend on market conditions. More specifically, news effects on exchange rates are larger in times when there is a high degree of market uncertainty and when previous exchange rate volatility has been large. 


\section{Introduction}

20 years after the influential paper by Meese and Rogoff (1983), only modest progress has been made in explaining and predicting exchange rate movements with macroeconomic fundamentals. While fundamentals-based models have been developed over the years that perform reasonably well in explaining exchange rate developments in the long-run, econometric attempts to explain short- and medium-term movements in exchange rates have had limited success so far. ${ }^{1}$ There is a broad consensus that some of the reasons for the poor performance of empirical models to account for exchange rate developments on a short- and medium-term horizon have not only to do with econometric problems, such as small sample biases, but also with irrationality of market participants, bubbles, herd behaviour etc., i.e. factors which are hard to capture in econometric models.

Over the past decade, two approaches have emerged in the literature that have made some progress in understanding exchange rate dynamics at short- to medium-term horizons. One of these approaches suggests that the chartist behaviour of market participants, i.e. the pursuit of technical trading rules that are unrelated to fundamentals, may account for some of the large movements and overshooting of currencies (Allen and Taylor 1990, Cheung and Chinn 1999, De Grauwe and Dewachter 1993). A more recent approach based on the seminal work by Evans and Lyons (2002) has shown that exchange rates at short horizons are to a significant extent driven by order flow, i.e. excess buyerinitiated or seller-initiated trading which reflects a market's information processing mechanism and which may be unrelated to existing macroeconomic fundamentals. However, Evans and Lyons (2003) and Love and Payne (2002) find that much of this order flow is in fact closely linked to news about fundamentals.

This paper takes a third approach to analysing the link between fundamentals and exchange rate movements. We argue that a potentially important shortcoming of standard, fundamentals-based models of the exchange rate is that they use measures of fundamentals that do not accurately reflect the true information market participants have when making trading decisions. In this paper, we use real-time data - similar to Andersen, Bollerslev, Diebold and Vega 2003, Faust, Rogers, Wang and Wright 2003 or Galati and Ho 2003 for the announcements of monetary policy decisions and important macroeconomic variables in the United States, Germany and the euro area, as measures of fundamentals. More precisely, exploiting survey data on market participants' expectations of such 
announcements, we are able to extract the surprise or "news" component of each variable. We then test whether these market news about fundamentals are capable of explaining the behaviour of daily exchange rate movements of the US dollar vis-à-vis the euro and German mark for the period 1993-2003. This approach has the key advantage of allowing us to test much more directly whether fundamentals - as they become available to market participants - can account for the price discovery process in foreign exchange markets.

The paper attempts to make a contribution to the literature in two central regards. First, it focuses on the presence of asymmetries in the reaction of exchange rates, and in particular on the question whether the reaction of the conditional means of exchange rates to macroeconomics news depends on existing market conditions. Such a non-linear behaviour is predicted, e.g. by the theoretical work on herd behaviour and information cascades (Banerjee 1992, Bikchandani, Hirschleifer and Welch 1992), or if agents use different information sets to forecast the future exchange rate (De Grauwe and Vansteenkiste 2002). Second, the paper provides an evaluation of the overall importance of macro news on exchange rates by analysing exchange rate responses at a daily rather than an intra-daily frequency, since intra-daily analyses show that the effects of news on exchange rates are generally very short-lived and often disappear within minutes (e.g. Dominguez 1999, Andersen, Bollerslev, Diebold and Vega 2003). We argue, however, that news about macroeconomic fundamentals are important for overall exchange rate movements only if these effects are longer-lived.

We find three key results. First, we show that news about fundamentals can explain relatively well the direction, but only to a much smaller extent the magnitude of exchange rate developments taking a medium-term, i.e. monthly horizon. We show that the exchange rate model using real-time data outperforms the same exchange rate model using vintage data: the former correctly explains $73 \%$ of the directional changes of the exchange rate, whereas the latter only accounts for $60 \%$ of the directional changes. This suggests that we can improve our understanding of movements in exchange rates at the short- to mediumterm horizon by focusing on real-time data.

Second, we find that news about the US economy have a larger impact on exchange rates than news emanating from the euro area. We show that this may reflect not only the relatively greater importance of the US economy, but is at least partly explained by the fact

\footnotetext{
${ }^{1}$ See e.g. Mark (1995) and Cheung, Chinn and Garcia Pascual (2002) for a discussion and evaluation of exchange rate models of the 1980 s and 1990s.
} 
that US announcements are usually released earlier than comparable euro area or German announcements, which gives US announcements a relatively higher news content.

A third important finding is that the effects of news on exchange rates are asymmetric in that they crucially depend on market conditions. More precisely, news releases have a particularly large effect on exchange rates when there is a high degree of market uncertainty, in the sense that previous news did not provide a clear signal about the direction of the economy. In addition, exchange rates tend to react more strongly to news in periods when previous exchange rate volatility has been high.

The paper is structured in the following way. We proceed in section 2 by outlining the rationale for using real-time data. Section 2 also discusses the construction of our data set, in particular how we extract market "news" about economic fundamentals. Section 3 then briefly outlines our econometric approach. The empirical results are presented in sections 4 and 5. Section 4 provides the results for the linear models, whereas Section 5 tests for the presence of asymmetries. An overall evaluation of the performance and goodness-of-fit of our real-time model follows in section 6. Section 7 concludes.

\section{Exchange rates, fundamentals and news: the data}

\subsection{Fundamentals and news: the case for using real-time data}

The issue of how to accurately measure economic fundamentals is a difficult one. Most empirical work, not only on the determination of exchange rates but more generally on most asset prices, employs the most recent vintage data, i.e. the final, revised figures that are generally released several months or quarters after the period to which the data refers. There are a number of problems with using such data. In particular, economic variables are mostly released only with a considerable time lag. Moreover, the first release of data on fundamentals is mostly revised at least once and in some cases several times. It often takes several quarters for the final data of an economic variable to be released. Therefore, using such final, revised data essentially tries to explain changes in asset prices with explanatory variables that are not known to market participants until several months later.

The use of real-time data instead, i.e. data that is actually available to economic agents at any one point in time, can fundamentally alter the results and interpretations of economic models. Orphanides (2001), for instance, finds that interpretations of monetary policy in the United States change fundamentally when using real-time data instead of 
vintage data when estimating Taylor rules. Koenig et al. (2000) show that the forecasts performance for US GDP changes substantially when using real-time data.

To illustrate the bias that may arise from the use of vintage data, Table 1 compares the quarterly advance US GDP releases, which usually occur the month after each quarter, with the preliminary and the final, revised GDP figures, which are mostly released two and three months, respectively, after each quarter. The table reveals that there are relatively large revisions in this data between the first (advance) and final release, which have been, on average, at the magnitude of 0.6 percentage points in the year-on-year quarterly GDP growth rate in 1993-2003. The table shows that most of the revision is made for the second release, the release of the "preliminary" GDP figures. The high correlations between the revisions and their surprise components in the data, shown in the last two columns, indicate that the revisions are indeed mostly unpredictable by the markets.

Although some previous work has analysed the effect of real-time data on foreign exchange markets, it has mostly focused on explaining changes in the conditional variances (e.g. Andersen and Bollerslev 1998, Ederington and Lee 1993). Only relatively few studies have so far attempted to test for the effect of real-time macroeconomic news on the conditional mean process of foreign exchange markets, as we do in this paper. Almeida, Goodhart and Payne (1998) look at the DM exchange rate vis-à-vis the US dollar and find significant intra-day effects of macroeconomic announcements. This is in line with some of those authors' earlier work (Goodhart, Hall, Henry, and Pesaran 1993), who find US and UK macroeconomic news to change the pound-US dollar exchange rate.

Two recent studies in this spirit are Andersen, Bollerslev, Diebold and Vega (2003) and Faust, Rogers, Wang and Wright (2003), who look at various currencies vis-à-vis the US dollar for the period 1992 till 1998 and 1987 till 2002, respectively. Using five-minute and 20-minute intervals, they find that various US macro news significantly affect exchange rates, with announcements relating to real activity and forward-looking news exerting the largest, and news about price developments relatively limited effects. An interesting result of the work by Andersen, Bollerslev, Diebold and Vega (2003) is that they find some indication for the presence of asymmetries in exchange rate responses to fundamentals, in that exchange rates tend to react more strongly to large news surprises and to negative news. Faust, Rogers, Wang and Wright (2003) provide evidence that for several real announcements, stronger than expected releases appreciate the dollar, but the announcement must imply a considerable future expected dollar depreciation. Finally, 
Galati and Ho (2003) analyse the exchange rate of the US dollar against the euro for the period 1999-2000, and find that for parts of their sample, the market responded dominantly to bad news from the euro area, while ignoring good news.

\subsection{Exchange rates and frequency issues}

Most of the previous work using real-time data focuses on intra-day data, usually 5-minute intervals, for analysing the effect of macroeconomic news on exchange rate levels. The paper by Galati and Ho (2003) provides an analysis at a daily frequency; however, their sample is restricted to 1999 and 2000. There are two key reasons why we chose not to use high-frequency data, and use daily data instead. First, there is some evidence that some

German releases are "leaked" to the markets prior to their official release time (Andersen, Bollerslev, Diebold and Vega 2003). A second reason is that asset prices may initially "overshoot" in their reaction to news (Faust, Rogers, Wang and Wright 2003). This may imply that the true permanent effect of news on exchange rates may be smaller than the initial, immediate reaction.

By contrast, the main drawback of choosing a daily frequency is that a large number of news, far larger than could possibly be measured and observed, "hits" the markets throughout a typical trading day. Hence our estimate of the news effect of any given macroeconomic variable includes noise from other news during the day. However, the important point to emphasise is that this does not lead to a bias in the estimates of news effects as long as the other news during the days of a particular announcement are not systematic or reflect other recurring news. It only means that the point estimates are not efficient, resulting in larger standard errors of the coefficients of the news effects.

We use the daily US dollar - euro/DEM rate at 18.00 Eastern Standard Time (EST), which implies that both European and US news are reflected in the exchange rate on the same day.

\subsection{Extracting market news about economic fundamentals}

The approach we follow in this paper is to analyse the relevance of real-time data of fundamentals for exchange rate movements at a daily frequency. The real-time data consists of the data releases for important macroeconomic variables as well as of monetary policy decisions, reflecting in real time the information that becomes available to the markets every day. 
However, it should be emphasised that on the day of the announcement, we can expect the markets to react only to the unexpected component, or "news" or "surprise", of an announcement. The remaining component of the announcement has been incorporated into the market previously, but since we cannot determine the exact timing of when this occurred, we cannot measure its impact on the markets to the same degree of accuracy.

Our measure of news is therefore the surprise component $\left(S_{k, t}\right)$ of the announcement $k$, which is defined as the difference between the actual announcement $\left(A_{k, t}\right)$ and the market's prior expectation $\left(E_{k, t}\right)$, normalised by dividing by the sample standard deviation $\Omega_{k}$ of each announcement in order to allow a comparison of the relative size of the coefficients in the econometric model:

$$
S_{k, t}=\frac{A_{k, t}-E_{k, t}}{\Omega_{k}}
$$

The data source for the macroeconomic variables is MMS International. The expectations data $\left(E_{t}\right)$ is the median of a survey of around 40 market participants on the Friday prior to each announcement. Our data set includes about 120 news for each variable, given the time period 1 January 1993 - 14 February 2003 and the fact that announcements for most variables occur on a monthly frequency.

Tables 2 and 3 show some summary and descriptive statistics of the macroeconomic variables for the United States, Germany and the euro area included in the model. Previous work using MMS expectations data shows that statistical tests confirm unbiasedness and efficiency of the survey data (Ehrmann and Fratzscher 2004). Finally, Figure 1 shows the non-standardised surprises for all the macroeconomic and monetary policy variables.

We also look at news about monetary policy decisions as a potential factor driving movements in the US dollar - euro/DEM exchange rate. Similar to the approach for the macroeconomic variables, we extract the market surprise about monetary policy decisions using survey data from Reuters. We define the monetary policy surprise as the difference between the actual announcement by the Fed, ECB or Bundesbank and the mean of the expectations of the around 25-30 market participants in the Reuters survey. As shown in our previous work on money markets (Ehrmann and Fratzscher 2004), this measure of monetary policy surprises proves not only unbiased and efficient statistically but performs 
relatively well empirically compared to other measures of such surprises. ${ }^{2}$ Table 4 presents some summary statistics for the monetary policy announcements and surprises for the three central banks and confirms that market participants were mostly able to anticipate monetary policy decisions well.

\section{Exchange rate responses to news: the econometric model}

We choose an iterative, weighted least squares (WLS) procedure, adopting a similar approach to Andersen, Bollerslev, Diebold and Vega (2003) and Ehrmann and Fratzscher (2004), in order to test for the news effects of daily announcement surprises and in order to account for the data characteristics described in the previous section. The benchmark model we estimate is

$$
\Delta\left(\ln e_{t}\right)=\alpha+\sum_{l 1=1}^{L 1} \gamma_{l 1} \Delta\left(\ln e_{t-l 1}\right)+\sum_{i=1}^{I} \beta_{i}^{E A} s_{i, t}^{E A}+\sum_{j=1}^{J} \beta_{j}^{U S} s_{j, t}^{U S}+\delta^{M} M o n+\delta^{F} F r i+\varepsilon_{t}
$$

where $e_{t}$ is the daily, nominal US dollar - euro/DEM exchange rate, ${ }^{3} s_{t}$ are the news surprises in each market, and Mon and Fri are included to account for potential day-of-theweek effects. Lags of the exchange rate change are also included to correct for possible autocorrelation, although in most cases a single lag was sufficient, which moreover was not always significant in the estimation.

Since the error term $\varepsilon_{\mathrm{t}}$ is non-normal and heteroskedastic, we correct for this by using an iterative WLS approach. The first step implies estimating equation (1) via OLS. The second step then estimates an equation for the residuals in the following way:

$$
\ln \left(\hat{\varepsilon}_{t}^{2}\right)=\omega+\sum_{l 2=1}^{L 2} \theta_{l 2} \ln \left(\hat{\varepsilon}_{t-l}^{2}\right)+\sum_{i=1}^{I} \kappa_{i}^{E A} n_{i, t}^{E A}+\sum_{j=1}^{J} \kappa_{j}^{U S} n_{j, t}^{U S}+\varphi^{M} M o n+\varphi^{F} F r i+\mu_{t}
$$

\footnotetext{
${ }^{2}$ For alternative measures for the United States based on Fed funds futures, see Kuttner (2001) and Söderström (2001). Such market-based measures could not be tested in the context of our analysis due to the non-availability of similar data for Germany.

${ }^{3}$ The exchange rate prior to 1999 is the US dollar - DEM rate with the DEM divided by its euro convergence rate in order to make the pre- and post-1999 periods comparable.
} 
with $n_{t}$ defined as the absolute values of the surprises $s_{t}$. In the third step, the estimated volatility $\exp \left(\ln \left[\hat{\varepsilon}_{t}^{2}\right]-\hat{\mu}_{t}\right)$ is then employed as instrument in the WLS estimation of equation (1). These three steps are iterated till convergence is achieved. ${ }^{4}$

Finally, we conducted different tests to control for possible multicollinearity problems resulting from the fact that some of the announcements occur on the same day. One way of doing this is to exclude from the model some of the news that frequently occur on the same day. However, the results did not change in any significant way. We therefore opted to keep all 25 monetary policy and macroeconomic news variables in the model.

\section{How important are fundamentals? Empirical results for linear models}

Table 5 presents the news effects on the US dollar - euro/DEM exchange rate for 12 US macroeconomic news, 11 German/euro area news, and the two monetary policy surprises in both areas for the full sample period of 1 January $1993-14$ February $2003 .^{5}$

\subsection{Exchange rate responses to news reflecting the real economy}

Most of the variables have the correct sign in that an improvement in real economic conditions in the United States leads to an appreciation of the US dollar (i.e. a lower US dollar - euro/DEM exchange rate) whereas good news in the euro area/Germany induce an appreciation of the euro/DEM vis-à-vis the US dollar, and analogously for negative news in the two areas. Overall, however, US news prove to be more important in driving exchange rate developments than euro area/German news.

Most of the variables for the real economy of the United States have indeed a statistically significant news effect on the exchange rate: an improvement in NAPM, a rise in non-farm payroll employment, higher GDP growth, higher consumer confidence, lower

\footnotetext{
${ }^{4}$ In principle, estimating such models in a GARCH framework would be superior due to the direct estimation of the conditional second moments in GARCH models. However, a GARCH specification could not be used in our context due to the large number of parameters in the model resulting from the inclusion of 25 different announcement news. This large number of parameters frequently led to problems in the convergence of the maximum likelihood estimation. Moreover, our results are also robust to estimating the model via OLS with heteroskedasticity and serial correlation consistent standard errors.

${ }^{5}$ We have conducted stability tests to exclude the possibility of parameter instability especially around the start of EMU on January $1^{\text {st }}, 1999$. However, we found the model to be stable over time. We have furthermore tested whether the inclusion of further euro area news might improve the fit of the model. We could not detect any variable that could add explanatory power, which is likely due to the fact that euro area news are generally released relatively late, and especially after the corresponding national releases (see Ehrmann and Fratzscher, 2004).
} 
unemployment and a longer workweek all lead to an appreciation of the US dollar. ${ }^{6}$ An improvement in the trade balance, faster growth in industrial production and larger retail sales also tend to appreciate the US dollar, though these variables are not statistically significant over the whole 1993-2003 sample period (see Table 5). To provide an order of magnitude of the news effects of fundamentals, for instance a surprise of one standard deviation in the advance US GDP measure leads, on average, to a $0.62 \%$ appreciation of the US dollar.

Most euro area/German economic fundamentals also have the correct sign in that an improvement in real conditions in the euro area/Germany lead to an appreciation of the euro/DEM. However, the IFO business confidence indicator is the only real economic variable of the euro area/Germany that is statistically significant over the full sample period. Nevertheless, the news impact of the IFO indicator is relatively large: an improvement in the IFO index by one standard deviation causes a $0.85 \%$ appreciation of the euro/DEM vis-à-vis the US dollar. One possible interpretation of this finding is that the importance of this variable may partly compensate for the lack of significance of other euro area news variables. In a market environment with a large number of news releases as is the case in the euro area where most countries provide additional data announcements for their own country - market participants may choose to turn to fewer indicators about the state of the real economy. It seems that the IFO index is such a benchmark indicator for the euro area. Moreover, it should be noted that the IFO index is one of the earliest data releases for Germany and the euro area, and thereby may also function as an indicator for market participants about what to expect about later data releases (see Figure 2).

In short, the results suggest that fundamentals about the real economy have a significant effect on the US dollar - euro/DEM exchange rate, which is in line with the results reported by Andersen, Bollerslev, Diebold and Vega (2003) and Faust, Rogers, Wang and Wright (2003).

\subsection{Exchange rate responses to monetary policy shocks}

In contrast to the real side of the economy, our theoretical prior for the effect of monetary policy news on exchange rates is ambiguous. Based on interest rate parity and arbitrage

\footnotetext{
${ }^{6}$ As noted by Harvey and Huang (1991), several of the US macro announcements are regularly made on Fridays. In our case this applies to unemployment, nonfarm payroll and workweek data, which are announced on Fridays at around $95 \%$ of all cases in our sample. We have tested whether the inclusion of the Friday dummy changes the coefficients, and found only negligible changes to the results. Similarly, including only
} 
conditions, an unanticipated monetary tightening by the Federal Reserve should induce an appreciation of the US dollar, while an unexpected tightening by the ECB/Bundesbank should lead to an appreciation of the euro/DEM after the news release of such a decision. ${ }^{7}$

However, the reaction of exchange rates to monetary policy decisions also depends on the market's interpretation of the underlying reasons for the decisions and the expected effect on the economy. For instance, an unexpected easing of monetary policy may signal to market participants that the real economy and other asset prices, such as equities, will receive a significant boost. Hence the easing of monetary policy in such a case may not lead to a depreciation but even to an appreciation of the exchange rate.

Table 5 shows that a shock to US monetary policy has a significant and large effect on the US dollar. The point estimate implies that an unexpected tightening of the federal funds target rate by 50 basis points causes a $0.8 \%$ appreciation of the US dollar against the euro. By contrast, unexpected monetary policy news by the Bundesbank and the ECB did not have a significant effect on the DEM and euro exchange rates vis-à-vis the US dollar.

\subsection{Exchange rate responses to news about price developments}

Concerning news in price developments, there is also no clear-cut theoretical prior as to how the exchange rate should react. On the one hand, higher than expected inflation may raise expectations of monetary policy tightening, entailing an immediate appreciation of the home currency. On the other hand, higher inflation implies, ceteris paribus, an appreciation of the real exchange rate. If purchasing power parity were to hold, a rise in inflation would require a depreciation of the nominal exchange rate.

In essence, the likely effect of price developments on the exchange rate crucially depends on the markets' beliefs about the central bank's monetary policy reaction function. If a central bank is perceived to give great importance to price stability, then an unexpected rise in inflation is likely to lead to an appreciation of the exchange rate. By contrast, if a

one of the labour market variables in the regression does not affect the results in any significant way. The different time variations in the variables are obviously sufficient to identify the different coefficients.

${ }^{7}$ Note that the medium- to longer-term reaction of the exchange rate to monetary policy shocks can be quite different from the immediate short-run effects. For uncovered interest rate parity to hold, the exchange rate needs to depreciate in the medium-run in response to monetary tightening in order to equalise returns after exchange rate adjustments. Moreover, rational expectations overshooting models in the vein of Dornbusch (1976) also imply a depreciation of the nominal exchange rate in the longer term - after an initial appreciation - as prices adjust gradually over time. However, the empirical evidence mostly rejects the hypothesis that exchange rates depreciate in the medium- and longer-term in response to contractionary monetary policy shocks. In fact, Eichenbaum and Evans (1995) and Evans (1994) find strong evidence for what they call "delayed overshooting" in that exchange rates continue to appreciate for a sustained period of time after 
central bank is believed to give less prominence to price developments or is believed not to react to a particular news about prices, then the second argument above may prevail and the exchange rate depreciates.

Table 5 reveals that the US CPI news are borderline significant at the $90 \%$ level with a positive sign. This implies that a rise in US inflation tends to lead, on average, to a depreciation of the US dollar. This is consistent with the second explanation given above.

\subsection{How important is the announcement timing?}

Besides the economic content of an announcement, it is likely that its effect on exchange rates depends on the lag between the announcement and the underlying economic fundamental. In other words, exchange rates are likely to react more strongly to the release of a leading indicator than to the release of the final revision of GDP, which refers to economic activity several months ago. Andersen, Bollerslev, Diebold and Vega (2003) provide some suggestive evidence in this direction, without conducting statistical tests. As can be seen in figure 2, the announcement timing varies strongly for the different variables. Some announcements (e.g. for US consumer confidence) are made towards the end of the month for the same month, or quickly afterwards (like the US NAPM indicator). Others are made more than two months later.

We test the hypothesis that announcement timing matters for the effect on exchange rates in two ways. First, we analyse whether the size of the estimated response is related to the announcement timing; and second, we test whether the significance of the estimated response differs according to the announcement lag. Hence, we regress the absolute values of the coefficients and t-statistics obtained in table 5 on the maximum announcement delay, which we measure by the maximum number of days that pass from the end of the month to which the announcement refers until its release. ${ }^{8}$ Table 6 reports the results.

Whereas the magnitude of a coefficient is only weakly related to its announcement timing, we find stronger effects of timing on the significance of the coefficients, estimated significantly at the $10 \%$ level. Each day of announcement delay makes the t-statistics in table 5 drop by 0.2 . This finding implies that economic content seems to govern the magnitude of responses, whereas announcement timing strongly determines the significance of the exchange rate response.

monetary policy tightening. These findings imply the existence of a conditional forward premium bias, i.e. a monetary policy induced forward premium bias.

${ }^{8}$ Using the shortest or medium delay yields similar results. 


\subsection{Exchange rate responses to composite indicators of macroeconomic news}

The lack of significant news effects emanating from German and euro area announcements need not imply that the exchange rate does indeed not react in a systematic fashion. It could similarly be that even a sample size spanning 10 years is not sufficient to capture the systematic effects of each individual announcement, especially if the exchange rate response depends on factors like the market conditions, or other special circumstances surrounding each announcement, like e.g. their size or sign. In order to increase the number of observations available for analysis in the remainder of this paper, we create two composite indicators capturing all macroeconomic variables in the US and all those in the euro area and perform further testing using this aggregated series.

For this purpose, we generate two indicator functions, one each for the United States $\left(\mathrm{I}^{\mathrm{US}}\right)$ and for the euro area $\left(\mathrm{I}^{\mathrm{EA}}\right)$, which indicate whether on any given day the respective market yields "good" news $\left(\mathrm{I}^{\mathrm{US}}=1, \mathrm{I}^{\mathrm{EA}}=1\right)$, "bad" news $\left(\mathrm{I}^{\mathrm{US}}=-1, \mathrm{I}^{\mathrm{EA}}=-1\right)$ or no news $\left(\mathrm{I}^{\mathrm{US}}=0, \mathrm{I}^{\mathrm{EA}}=0\right)$. "Good" news are defined as those news that, based on our findings presented in sections 4.1-4.3, are expected to lead to an appreciation and "bad" news to a depreciation of the respective currencies. ${ }^{9}$ Hence the two indicator functions aggregate all domestic news into a single indicator for each country. We then formulate the modified version of equation (1) as

$$
\Delta\left(\ln e_{t}\right)=\alpha+\sum_{l 1=1}^{L 1} \gamma_{l 1} \Delta\left(\ln e_{t-l 1}\right)+\beta^{E A} I_{t}^{E A}+\beta^{U S} I_{t}^{U S}+\delta^{M} M o n+\delta^{F} F r i+\varepsilon_{t}
$$

We estimate equation (3) using the WLS methodology described in section 3, with results for German and US news reported in the first rows of tables 7 and 8, respectively. Due to the pooling of all domestic macroeconomic variables into a single measure, the estimates of the size of the exchange rate response become statistically significant, with each parameter showing the expected sign.

The drawback of this approach of course is that the coefficients can be interpreted only as average measures of the news effects of a country's fundamentals and hide the heterogeneity of the importance of individual variables, as outlined in sections 4.1-4.3.

\footnotetext{
${ }^{9}$ On days with more than one announcement, we took the news of the relatively more important variable, based on our findings in section 4.1. Moreover, due to the ambiguousness of the sign for the price variables, we tested the inclusion of the price variables with the opposite sign, but did not find any significant differences in the econometric results. Also note that monetary policy shocks are not included in this indicator functions.
} 
However, the key point we want to make with this analysis is that also euro area news about fundamentals have an important and significant effect on the exchange rate, even if this effect is somewhat smaller than that of US fundamentals.

\section{Asymmetries in exchange rate responses to news of fundamentals}

Since the linear benchmark model of section 4 can only reveal average, systematic reactions of the exchange rate, it is necessary to analyse whether the reaction is indeed time invariant, or whether news effects of fundamentals depend on factors like the existing market conditions. Work on herd behaviour (Banerjee 1992) and informational cascades (Bikchandani et al. 1992), for instance, show that economic agents may interpret, process and react to information in very different ways depending on the conditions and the environment in which they operate. In particular, the news content of any given news may be larger if there is a high degree of uncertainty in the markets and market participants search for guidance about the future course of the economy.

The aim of this section is to analyse whether such asymmetries are present in foreign exchange markets. While there has been some work on this issue for bond markets (Fleming and Remolona 1997), such analysis is quite novel for foreign exchange markets. ${ }^{10}$ We analyse the role of different measures of market uncertainty, looking at the size and sign effects of news (section 5.1), and at exchange rate volatility and uncertainty about the future direction of the economy (section 5.2).

\subsection{Size effects and sign effects of news}

There is a broad literature for equity markets showing that stock prices react more strongly to negative news than to positive ones. The underlying reason for this asymmetry lies in the interaction of what is commonly known as leverage effects and volatility feedback effects. ${ }^{11}$ The argument is that a shock affects the level of asset prices not only directly by changing the state of the world - altering the leverage of firms - but also by changing the volatility of asset prices. A positive shock raises the stock price of a firm by improving its leverage, but at the same time the increased volatility lowers the stock's value because

\footnotetext{
${ }^{10}$ Galati and Ho (2001) conduct some asymmetry tests for exchange rates and find mixed evidence for the short period of 1999-2000. Andersen, Bollerslev, Diebold and Vega (2003) find responses to vary depending on the sign of the news and the uncertainty of the forecast.

${ }^{11}$ For instance, Campbell and Hentschel (1992) provide a nice discussion and compelling empirical evidence for the presence of such effects for equity markets.
} 
risk-averse investors require higher returns for bearing the additional risk. In case of a positive shock, leverage effects and volatility feedback effects have the opposite effect on the asset price while the two effects are mutually reinforcing in case of negative shocks. Thus, negative shocks tend to have a larger effect on the level of equity prices.

We test for the presence of such sign effects for foreign exchange markets by using the same indicator function of section 4.5, distinguishing between "good" news, "bad" news and no news in the foreign exchange market. To check for the difference between the effects of such positive news and negative news, we estimate the model

$$
\begin{aligned}
\Delta\left(\ln e_{t}\right) & =\alpha+\sum_{l 1=1}^{L 1} \gamma_{l 1} \Delta\left(\ln e_{t-l 1}\right)+\left(\beta_{P}^{E A} D_{P, t}^{E A}+\beta_{N}^{E A} D_{N, t}^{E A}\right) I_{t}^{E A} \\
& +\left(\beta_{P}^{U S} D_{P, t}^{U S}+\beta_{N}^{U S} D_{N, t}^{U S}\right) I_{t}^{U S}+\delta^{M} M o n+\delta^{F} F r i+\varepsilon_{t}
\end{aligned}
$$

with $D_{P, t}=1$ if the news is positive $\left(I_{t}=1\right)$ and $D_{N, t}=1$ if the news is negative $\left(I_{t}=-1\right)$, both dummies being zero otherwise. The estimation therefore enables us to compare the coefficient for the effect of good news $\left(\beta_{P}\right)$ with the one for negative news $\left(\beta_{N}\right)$, for both the United States and the euro area.

The second row in Table 7 shows that only negative news in Germany/ the euro area have a statistically significant effect on the exchange rate, in line with the findings reported by Galati and Ho (2003). However, there is no such evidence for the United States, where the point estimate is similar for both types of news, and both are estimated to be statistically significant. $^{12}$

A question related to the one on sign effects is whether large shocks have a bigger impact than smaller ones. The rationale for such size effects, again widely confirmed for the analysis of other asset prices, is that larger shocks may contain a proportionally larger news content, thus causing a larger adjustment of the exchange rate. We define the model for testing this hypothesis in a similar way to equation (4), only now that $D_{P, t}=1$ if the news is in the highest or the lowest quartile of the distribution and $\mathrm{D}_{\mathrm{N}, \mathrm{t}}=1$ if the news is in the middle two quartiles of the distribution. The third row in table 7 shows evidence for such size effects for Germany/the euro area: it is the large surprises that exert a statistically significant impact on exchange rates, whereas small surprises are insignificant.

\footnotetext{
${ }^{12}$ Unfortunately, statistical tests on differences between the coefficients in the right and left panels of tables 7 and 8 do generally not show any significant difference.
} 
Overall, the findings provide support for the hypothesis that the reaction of exchange rate to macroeconomic news depends both on the sign as well as the size of the news that reaches the financial markets.

\subsection{The importance of uncertainty}

Theoretical and empirical models of news and uncertainty have argued that market participants may react more strongly to news in periods when they are uncertain about the state and direction of the economy (e.g. Veronesi 1999). To investigate this link in our context, we test whether the exchange rate reacts more strongly to news when uncertainty among market participants is high. We explore different proxies for uncertainty.

First, we ask whether news have a larger effect if previous exchange rate volatility has been high. We therefore define high market uncertainty as the situation when exchange rate volatility was above its sample mean during the previous one week, one month, two months etc. till one year. Which of these time horizons is most sensible essentially depends on the memory and previous experience of market participants. It seems that market participants may give greater weight to the immediate past and we therefore prefer the volatility measures with shorter horizons, but nevertheless test also for longer horizons.

Our econometric model is similar to the one of equation (4), only that now $D_{P, t}=1$ if the exchange rate volatility over the previous 1 week or 1 month etc. was above its sample mean, and $D_{N, t}=1$ if the volatility was below its mean. Row 4 in tables 7 and 8 reveal that the news effects of fundamentals are particularly significant if exchange rate volatility was high during the previous week, for both the United States and the euro area. Using longer time horizons for measuring exchange rate volatility does not change this finding. Second, we test whether news have larger effects on exchange rates during periods when markets were surprised by previous news systematically in the same fashion, e.g. if there has been a series of positive surprises or an accumulation of negative surprises over the last period. The hypothesis in the vein of the influential work by Veronesi (1999) is therefore that markets react less to news when previous news have been pointing in the same direction, i.e. if they have been persistently more positive or persistently more negative than expected, and more if previous news were contradictory to one another.

As before, such a measure can be calculated over different time horizons. Choosing a three-month horizon, we define the history of surprises to be of different signs if the cumulated surprises of $I_{t}$ over the past one month were in the middle two quartiles of its 
distribution. Accordingly, the history of surprises is defined to be of the same sign if these cumulated surprises are either very positive - i.e. in the top quartile - or very negative - in the bottom quartile of the distribution. Our econometric model is again similar to the one of equation (4), only that now $D_{P, t}=1$ if the history of surprises shares the same sign, and $D_{N, t}=1$ if the history has mixed signs

The results reported in rows 5 and 6 of Tables 7 and 8 show that the effects of German announcements are estimated significantly only in the case of a history with mixed surprises in Germany, whereas US announcements exert significant effects in all scenarios. These findings again confirm the importance and dominance of the US market as the main determinant for the relevance of news effects of fundamentals on the US dollar euro/DEM exchange rate.

Third, an alternative way to analyse the role of uncertainty is to test whether news have a larger effect in periods when there have been many large surprises in the recent weeks and months. The intuition is as follows. The occurrence of several large surprises means that market participants have not been able to forecast well the economic environment. Thus in a period when there were several large news surprises in the recent past, investors may attach more weight and react more strongly to new announcements. Formally, a period of "high domestic uncertainty", as in row 7 of Tables 7 and 8 , is defined when there have been more large than small surprises over the past one month, three months, etc. In this context, we define a surprise to be large if it is above its average value.

Row 7 shows the results when accounting only for domestic news, while row 8 shows results taking into account news in the United States and the euro area. The findings are convincing as they show that both the US and the euro area markets react significantly to news only in periods of high domestic uncertainty. For German announcements, this conclusion also holds when defining uncertainty to include the surprises emanating from the United States (row 8 of Table 7). Overall, the findings provide support to the hypothesis that markets react more to news in an environment of uncertainty.

\section{Evaluating the real-time model of fundamentals and exchange rates}

We have so far shown that fundamentals have indeed a significant and time-varying effect on exchange rates on a daily basis. What we have not answered yet is how well fundamentals can explain overall changes in exchange rates, i.e. to evaluate the goodness- 
of-fit of our real-time model. This is an important question because the statistical significance of parameter estimates for daily fundamentals by itself does not necessarily imply that fundamentals explain well the magnitude or even the direction of exchange rate movements in the short- to medium-term.

For this purpose, we take the coefficients obtained from estimating equation (1) and multiply these with their respective announcement news for each variable and in each month. ${ }^{13}$ Adding up the effects for all fundamentals in each month allows us to compare the actual change in the US dollar - euro/DEM exchange rate with the one explained by the fundamentals of our model.

Figure 3 shows the actual and the predicted exchange rate developments of the US dollar - euro/DEM for the period January 1993 - February 2003. The chart shows the large degree of variability of the exchange rate over the period, with first the DEM appreciating vis-à-vis the US dollar till early 1995 and then the US dollar appreciating until 2001. The exchange rate predicted on the basis of our news surprises is much smoother. Given the way the real-time model is set up, this finding is consistent with what we expected: market participants generally are reasonably good in correctly anticipating announcements about fundamentals. As we have shown, market expectations are unbiased and efficient, and therefore there should be no large swings in the real-time model based on news surprises.

Nevertheless, the real-time model based on surprises correctly indicates the general trend of the exchange rate over time: that is, an expected appreciation of the US dollar between 1995 and late 1999, and a recovery of the euro thereafter. What this implies is that during the period 1995-1999, economic agents were, on average, relatively more positively surprised by economic news in the United States than in Europe. This is intuitively convincing as the United States moved from a recession in the early 1990s to a tremendous economic boom in the late 1990s, during which the economic performance of the US economy outpaced that of the euro area and Germany. After 2000, the US economy slowed down much more significantly, albeit from a higher level, than the euro area economy. This created more negative news about the US economy than for the euro area, and hence our model predicts an appreciation of the euro between late 2000 and $2003 .{ }^{14}$ Overall,

\footnotetext{
${ }^{13}$ The reasons for moving from daily frequency to monthly frequency are that many days in our model do not have any announcements, and also the fact that actual and predicted exchange rate developments become more easily comparable graphically when using a lower frequency than daily data.

${ }^{14}$ Note that these temporary trends in the model with news is not inconsistent with the unbiasedness and efficiency of the expectations of market participants. Of course in the long-run, the predicted exchange rate should not change significantly from its original level in order for the unbiasedness and efficiency of the expectations data to hold.
} 
when looking at the whole sample period 1993-2003, the US dollar - euro/DEM change predicted by the model is almost identical to the overall change in the actual exchange rate.

Given that market participants do not make systematic mistakes in their expectations, one therefore cannot expect the model with news surprises to explain the exchange rate movement in the medium-term. Recall that the news $s_{t}$ in our model capture only a small part of the information about fundamentals that are actually incorporated into the markets, namely the unexpected component of an announcement. The expected component has been incorporated previously, but since we do not know when this information has been incorporated we cannot measure its effect on the exchange rate in the econometric model.

As a second step, to capture the effect of the full announcement - i.e. the unexpected component as well as the expected component - we make the assumption that the expected component is incorporated into the exchange rate in the same way the unexpected one is. We therefore use the coefficients obtained from estimating equation (1) and multiply these with the change in the announcement of each fundamental. We then aggregate the effects of all variables to get the predicted overall effect of fundamentals on the exchange rate.

Figure 4 shows the predicted and the actual exchange rates based on this exercise. The predicted exchange rate now moves much more and tracks significantly better the large swings in the actual US dollar - euro/DEM exchange rate. Although the predicted rate does again not explain the large magnitude in the exchange rate swings, it nevertheless does a reasonable good job in tracking the direction of the exchange rate movements. The short-lived appreciation of the US dollar in 1993 is tracked as well as the subsequent appreciation of the DEM till 1995. The model anticipates correctly part of the US dollar appreciation between 1995 and 1999. Moreover, the model tracks reasonably well the overall appreciation of the euro between late 2000 and early 2003. However, the period for which the model performs poorly is from mid-1999 to the end of 2000. In this period, the US dollar appreciated by about $20 \%$ vis-à-vis the euro whereas our model does not anticipate any change in the exchange rate or even a slight depreciation of the US dollar. Interestingly, this period largely coincides with the sample tested by Galati and Ho (2003), which have found the exchange rate to respond dominantly to bad news emanating from the euro area, while ignoring good news.

As the third and final step of the goodness-of-fit analysis, we would like to know how the model with real-time data compares to a model using vintage data. Since vintage data becomes available with a delay of often several months, we cannot assign a particular 
day to when the vintage data is incorporated into prices. We do therefore perform the test at monthly rather than daily frequency, and use the change in the announced data compared to the previous announcement $\left(\Delta A_{t}\right)$ rather than the surprise component of the announcement $\left(s_{t}\right)$. Basically, this assumes that information on the change in the announced data is priced in by the market within the month of the announcement. The model is thus:

$$
\Delta\left(\ln e_{t}\right)=\alpha+\sum_{l 1=1}^{L 1} \gamma_{l 1} \Delta\left(\ln e_{t-l 1}\right)+\sum_{i=1}^{I} \beta_{i}^{E A} \Delta A_{i, t}^{E A}+\sum_{j=1}^{J} \beta_{j}^{U S} \Delta A_{j, t}^{U S}+\delta^{M} M o n+\delta^{F} F r i+\varepsilon_{t}
$$

and the volatility equation

$$
\ln \left(\hat{\varepsilon}_{t}^{2}\right)=\omega+\sum_{l 2=1}^{L 2} \theta_{l 2} \ln \left(\hat{\varepsilon}_{t-l}^{2}\right)+\sum_{i=1}^{I} \kappa_{i}^{E A}\left|\Delta A_{i, t}^{E A}\right|+\sum_{j=1}^{J} \kappa_{j}^{U S}\left|\Delta A_{i, t}^{U S}\right|+\varphi^{M} \text { Mon }+\varphi^{F} F r i+\mu_{t}
$$

now with the absolute values of the announcement changes $\left(\left|\Delta A_{t}\right|\right)$.

Table 9 compares the absolute changes and the correctly explained directional changes of the model (5)-(6) with real-time data with the same model but where the announcement changes are based on vintage data. Both models still account for a small proportion of the magnitude in absolute monthly exchange rate movements. However, the real-time data model performs markedly better in explaining directional changes than the vintage data model. The model with real-time data explains correctly $73 \%$ of the monthly exchange rate changes compared to only $60 \%$ of the vintage data model for the full period $1993-2003$ and $58 \%$ for $1999-2003$. Overall, the ability to account for about $75 \%$ of the monthly directional changes in the US dollar-euro exchange rate also compares very favourably to other standard models in the literature using vintage data (see e.g. Cheung, Chinn and Garcia Pascual 2002).

\section{Conclusions}

The paper presented evidence that monetary policy and macroeconomic fundamentals are indeed an important driving force behind exchange rate movements. The approach the paper took is relatively novel for the analysis of exchange rates in that we look at the role 
of news about fundamentals. By extracting the news component of macroeconomic announcements with the help of market expectations based on survey data, the paper tested to what extent such real-time news in the United States and in the euro area/Germany affected the US dollar - euro/DEM exchange rate during the period 1993-2003.

The empirical findings confirm that news about fundamentals have a significant effect on the exchange rate. Economic developments in the United States prove to play a bigger role in explaining exchange rate movements than economic news in the euro area and in Germany. We show that this finding may not only reflect the relatively greater importance of the US economy, but that it is at least in part due to the fact that US announcements are usually released earlier than euro area or German announcements. The implication is that US announcements have a relatively higher news content than comparable euro area announcements.

A key result of the paper is that the effect of fundamentals on exchange rates depends on market conditions. We find that news about fundamentals have a particularly big impact in an environment of high market uncertainty and large previous exchange rate volatility. In addition, the results suggest that negative news and large unexpected news have a larger effect on exchange rates than positive and smaller unexpected announcement surprises.

Robustness and goodness-of-fit tests show that our model with real-time data does well in explaining the direction though not the magnitude of monthly exchange rate changes. In particular, we find that an exchange rate model with real-time data substantially outperforms the same model using vintage data. Overall, the findings of the paper suggest that looking at real-time data - that is, information that is actually available to market participants when making their trading and investment decisions - may help us better understand and track the importance of fundamentals for exchange rate developments.

Several open questions arise from the paper. In particular, why does the real-time data model do a good job in explaining the direction but not the magnitude of exchange rate changes? Is this due to the fact that we exclude or cannot measure other relevant news that point in the same direction as the available real-time data? Or is this explained by the overreaction of markets, related to factors such as bubbles or herd behaviour, which goes beyond the public information that becomes available to the markets? A more comprehensive approach to modelling exchange rate which combines the three different approaches of news effects, order flow and chartist behaviour may prove a promising avenue to disentangle these issues. 


\section{References}

Allen, H. and M. Taylor (1990). Charts, Noise and Fundamentals in the London Foreign Exchange Market. Economic Journal, 100: 49-59.

Almeida, A., Goodhart, C. and R. Payne (1998). The Effects of Macroeconomic 'News' on High Frequency Exchange Rate Behavior. Journal of Financial and Quantitative Analysis 33: 383-408.

Andersen, T. and T. Bollerslev (1998). Deutsche Mark-Dollar Volatility: Intraday Activity Patterns, Macroeconomic Announcements, and Longer Run Dependencies. Journal of Finance 53: 219-265.

Andersen, T.G., Bollerslev, T., Diebold, F.X. and Labys, P. (2001). The Distribution of Realized Exchange Rate Volatility. Journal of the American Statistical Association 94: 42-55.

Andersen, T., Bollerslev, T., Diebold, F. and C. Vega (2003). Micro Effects of Macro Announcements: Real-Time Price Discovery in Foreign Exchange. American Economic Review 39(1): 38-62.

Banerjee, A. (1992). A Simple Model of Herd Behavior. Quarterly Journal of Economics 93(3): 797-817.

Bikchandani, S., Hirschleifer D. and I. Welch (1992). A Theory of Fads, Fashion, Custom and Cultural Change as Informational Cascades. Journal of Political Economy 100: 992-1026.

Campbell, J. and L. Hentschel (1992). No News is Good News: An Asymmetric Model of Changing Volatility in Stock Returns. Journal of Financial Economics 31: 281-318.

Cheung, Y., and M. Chinn (1999). Macroeconomic Implications of the Beliefs and Behaviour of Foreign Exchange Traders. NBER Working Paper No. 7417.

Cheung, Y., Chinn, M. and A. Garcia Pascual (2002). Empirical exchange rate models of the nineties: Are any fit to survive? NBER Working Paper No. 9393, December.

De Grauwe, P. and I. Vansteenkiste (2002). Exchange Rates and Fundamentals: A Nonlinear Relationship? De Nederlandsche Bank Staff Reports No. 78/2002

Dominguez, K.M. (1999). The Market Microstructure of Central Bank Intervention, NBER Working Paper No 7337.

Dornbusch, R. (1976). Expectations and Exchange Rate Dynamics. Journal of Political Economy 84: 1161-1176.

Ederington, L. and J. Lee (1993). How Markets Process Information: News Releases and Volatility. Journal of Finance 48: 1161-1191.

Ehrmann, M. and M. Fratzscher (2004). Equal size, equal role? Interest rate interdependence between the euro area and the United States. ECB Working Paper 342; Board of Governors of the Federal Reserve System International Finance Discussion Papers No. 800, April 2004.

Eichenbaum, M. and C. Evans (1995). Some Empirical Evidence on the Effects of Shocks to Monetary Policy on Exchange Rates. Quarterly Journal of Economics 110(4): 975-1009.

Evans, C. (1994). Interest Rate Shocks and the Dollar. Economic Perspectives, Federal Reserve Bank of Chicago 18, 11-24.

Evans, M. and R. Lyons (2002). Order Flow and Exchange Rate Dynamics. Journal of Political Economy 110: 170-180.

Evans, M. and R. Lyons (2003). How is Macro News Transmitted to Exchange Rates? NBER Working Paper No 9433. 
Faust, J., Rogers, J.H., Wang, S.B. and J.H. Wright (2003). The High-Frequency Response of Exchange Rates and Interest Rates to Macroeconomic Announcements. Board of Governors of the Federal Reserve System International Finance Discussion Paper No. 784.

Fleming, M. and E. Remolona (1997). What Moves the Bond Market? Federal Reserve Bank of New York Economic Policy Review 3(4): 31-50.

Fleming, M and E. Remolona (1999). Price Formation and Liquidity in the U.S. Treasury Market: The Response to Public Information. Journal of Finance 54: 1901-1915.

Frankel, J. and A. Rose (1995). A Survey of Empirical Research on Nominal Exchange Rates. In G. Grossman and K. Rogoff (eds.): Handbook of International Economics. Amsterdam: North-Holland.

Galati, G. and C. Ho. (2003). Macroeconomic News and the Euro/Dollar Exchange Rate. Economic Notes, Banca Monte dei Paschi di Siena, 32(3): 371-398.

Goodhart, C., Hall, S., Henry S. and B. Pesaran (1993). News Effects in a High-Frequency Model of the Sterling-Dollar Exchange Rate. Journal of Applied Econometrics 7: 199-211.

Harvey, C.R. and R.D. Huang (1991). Volatility in the Foreign Currency Futures Market. Review of Financial Studies 4: 543-569.

Koenig, E., Dolmas, S., and J. Piger (2000). The Use and Abuse of "Real-Time" Data in Economic Forecasting. International Finance Discussion Paper No. 684, Federal Reserve Board of Governors, November 2000.

Kuttner, K. (2001). Monetary Policy Surprises and Interest Rates: Evidence from the Fed Funds Futures Market. Journal of Monetary Economics 47, 523-544.

Love, R. and R. Payne (2002). Macroeconomic News, Order Flow, and Exchange Rates. Mimeo, London School of Economics.

Mark, N.C. (1995). Exchange Rates and Fundamentals: Evidence on Long-Horizon Predictability, American Economic Review 85: 201-218.

Meese, R. and K. Rogoff (1983). Empirical Exchange Rate Models of the Seventies: Do They Fit Out of Sample? Journal of International Economics 14: 3-24.

Orphanides, A. (2001). Monetary Policy Rules Based on Real-Time Data. American Economic Review 91(4): 964-985.

Perez-Quiros, G. and J. Sicilia (2002). Is the European Central Bank (and the United States Federal Reserve) Predictable? ECB Working Paper 192, November 2002.

Söderström, U. (2001). Predicting Monetary Policy with Federal Funds Futures Prices. Journal of Futures Markets 21(4), 377-391.

Veronesi, P. (1999). Stock Market Overreaction to Bad News in Good Times: A Rational Expectations Equilibrium Model, Review of Financial Studies 12: 975-1007. 


\section{Appendix}

Table 1: Real-time versus vintage data:

the example of US GDP, 1993-2003

\begin{tabular}{cccccc}
\hline & \multicolumn{2}{c}{ mean of absolute revisions in US GDP } & \multicolumn{2}{c}{ correlation between surprise \& } \\
& $\begin{array}{c}\text { advance vs. } \\
\text { preliminary }\end{array}$ & $\begin{array}{c}\text { preliminary } \\
\text { vs. final }\end{array}$ & $\begin{array}{c}\text { advance vs. } \\
\text { final }\end{array}$ & $\begin{array}{c}\text { preliminary } \\
\text { revision }\end{array}$ & $\begin{array}{c}\text { final }^{1} \\
\text { revision }^{2}\end{array}$ \\
$1993-2003$ & $0.51 \%$ & $0.21 \%$ & $0.61 \%$ & 0.53 & 0.86 \\
$1993-1996$ & $0.49 \%$ & $0.21 \%$ & $0.56 \%$ & 0.56 & 0.74 \\
$1997-2000$ & $0.50 \%$ & $0.23 \%$ & $0.63 \%$ & 0.59 & 0.98 \\
$2001-2003$ & $0.56 \%$ & $0.19 \%$ & $0.68 \%$ & 0.62 & 0.97 \\
\hline
\end{tabular}

Notes:

${ }^{1}$ correlation coefficient between preliminary GDP revision and surprise of preliminary GDP announcement.

${ }^{2}$ correlation coefficient between final GDP revision and surprise of final GDP announcement. 
Table 2: Macroeconomic announcements, release dates and times

\begin{tabular}{lcccccc}
\hline \multicolumn{1}{c}{ Announcement } & Period & & \# Observ. & $\begin{array}{c}\text { Usual } \\
\text { Release }\end{array}$ & $\begin{array}{c}\text { intra-month } \\
\text { min }\end{array}$ & $\begin{array}{c}\text { lag: \# of } \\
\text { max }\end{array}$ \\
months
\end{tabular}

Source: MMS. 
Table 3: Summary statistics for macroeconomic announcements, surveys, and surprises

\begin{tabular}{|c|c|c|c|c|c|c|}
\hline \multirow[b]{2}{*}{ Announcement } & \multicolumn{2}{|c|}{ Announcement } & \multicolumn{2}{|c|}{ Survey } & \multicolumn{2}{|c|}{ Surprise } \\
\hline & Mean & Std. Dev. & Mean & Std. Dev. & Mean & Std. Dev. \\
\hline \multicolumn{7}{|l|}{ Germany } \\
\hline GDP Q/Q (\%) & 0.346 & 0.641 & 0.322 & 0.607 & 0.024 & 0.212 \\
\hline Ifo Business Climate Index & 95.009 & 5.256 & 95.048 & 4.325 & -0.039 & 1.162 \\
\hline Business confidence balance & -4.185 & 7.458 & -4.519 & 7.802 & 0.333 & 1.000 \\
\hline PPI M/M (\%) & 0.069 & 0.275 & 0.094 & 0.163 & -0.026 & 0.215 \\
\hline Retail Sales, real SA M/M (\%) & -0.795 & 3.044 & -0.732 & 1.732 & -0.063 & 2.781 \\
\hline Trade Balance & 4.691 & 1.894 & 4.353 & 1.330 & 0.338 & 1.442 \\
\hline M3 Y/Y (\%) & 6.294 & 4.711 & 5.853 & 3.933 & 0.441 & 1.872 \\
\hline Unemployment & 6.009 & 31.292 & 3.126 & 20.475 & 2.883 & 23.194 \\
\hline CPI M/M (\%) & 0.159 & 0.231 & 0.154 & 0.187 & 0.005 & 0.128 \\
\hline Industrial production SA M/M (\%) & 0.183 & 1.945 & 0.197 & 0.815 & -0.014 & 1.742 \\
\hline Manufacturing orders M/M (\%) & 0.278 & 2.401 & 0.128 & 0.889 & 0.150 & 2.185 \\
\hline \multicolumn{7}{|l|}{ USA } \\
\hline Real GDP (S.A.A.R.) Advance $Y / Y(\%)$ & 3.234 & 1.735 & 2.830 & 1.592 & 0.404 & 0.772 \\
\hline Consumer confidence & 110.188 & 23.523 & 109.466 & 23.204 & 0.723 & 4.960 \\
\hline CPI M/M (\%) & 0.204 & 0.169 & 0.227 & 0.111 & -0.023 & 0.119 \\
\hline Housing starts & 1.503 & 0.152 & 1.489 & 0.134 & 0.013 & 0.069 \\
\hline Industrial production SA M/M (\%) & 0.209 & 0.490 & 0.161 & 0.347 & 0.048 & 0.253 \\
\hline N.A.P.M. & 51.812 & 4.683 & 51.974 & 4.431 & -0.162 & 1.933 \\
\hline Nonfarm payrolls & 152.759 & 174.240 & 161.045 & 108.197 & -8.286 & 118.643 \\
\hline PPI M/M (\%) & 0.102 & 0.420 & 0.165 & 0.193 & -0.063 & 0.304 \\
\hline Retail sales (\%) & 0.318 & 0.921 & 0.332 & 0.502 & -0.014 & 0.652 \\
\hline Trade balance & -16.349 & 8.676 & -16.163 & 8.716 & -0.186 & 1.837 \\
\hline Unemployment rate (\%) & 5.179 & 0.911 & 5.220 & 0.934 & -0.042 & 0.143 \\
\hline Average workweek & 34.376 & 0.191 & 34.386 & 0.190 & -0.010 & 0.094 \\
\hline
\end{tabular}

Source: MMS, authors' calculations. 
Table 4: Summary statistics for monetary policy announcements, surveys, and surprises

\begin{tabular}{|c|c|c|c|c|c|c|c|c|}
\hline \multirow[b]{2}{*}{$\begin{array}{l}\text { Monetary policy } \\
\text { announcements }\end{array}$} & \multicolumn{2}{|c|}{ Announcement } & \multicolumn{2}{|c|}{ Survey } & \multicolumn{4}{|c|}{ Surprise } \\
\hline & $\begin{array}{l}\text { Number of } \\
\text { meetings }\end{array}$ & $\begin{array}{l}\text { Mean abs. } \\
\text { announc.* }\end{array}$ & $\begin{array}{l}\text { Mean abs. } \\
\text { survey* }\end{array}$ & Std. Dev. & $\begin{array}{l}\text { Mean abs. } \\
\text { surprise* }\end{array}$ & Std. Dev. & $\begin{array}{l}\text { Number c } \\
\text { "correct" }\end{array}$ & $\begin{array}{l}\text { forecasts } \\
\text { "false" ** }\end{array}$ \\
\hline Federal Reserve & 78 & 0.144 & 0.120 & 0.211 & 0.049 & 0.112 & 65 & 13 \\
\hline Bundesbank & 144 & 0.040 & 0.025 & 0.066 & 0.044 & 0.113 & 127 & 17 \\
\hline ECB & 72 & 0.052 & 0.041 & 0.086 & 0.044 & 0.087 & 61 & 11 \\
\hline $\begin{array}{l}\text { Monetary policy } \\
\text { changes }\end{array}$ & $\begin{array}{l}\text { Number of } \\
\text { changes }\end{array}$ & $\begin{array}{l}\text { Mean abs. } \\
\text { changes* }\end{array}$ & $\begin{array}{l}\text { Mean abs. } \\
\text { survey* }^{*}\end{array}$ & Std. Dev. & $\begin{array}{l}\text { Mean abs. } \\
\text { surprise* }^{*}\end{array}$ & Std. Dev. & $\begin{array}{l}\text { Number c } \\
\text { "correct" }\end{array}$ & $\begin{array}{l}\text { forecasts } \\
\text { "false" ** }\end{array}$ \\
\hline Federal Reserve & 31 & 0.363 & 0.281 & 0.334 & 0.102 & 0.173 & 23 & 8 \\
\hline Bundesbank & 13 & 0.442 & 0.120 & 0.120 & 0.322 & 0.114 & 1 & 12 \\
\hline ECB & 12 & 0.354 & 0.147 & 0.190 & 0.207 & 0.249 & 4 & 8 \\
\hline
\end{tabular}

Notes:

* Means are calculated from the absolute numbers of the announcements, surveys and surprises.

** A "correct" forecast is defined as an absolute surprise of within \pm 12.5 basis points of the announcement or change.

Source: Federal Reserve, Bundesbank, ECB, Reuters, own calculations. 
Table 5: Exchange rate response to individual macro and monetary policy variables WLS model of equation (1), 1993-2003

\section{German announcement surprises}

\section{US announcement surprises}

\begin{tabular}{lcclll}
\hline Monetary policy & -0.590 & $(-1.304)$ & Monetary policy & $-1.616^{* *}$ & $(-2.364)$ \\
CPI & -0.034 & $(-0.309)$ & N.A.P.M. & $-0.526^{* * *}$ & $(-3.351)$ \\
M3 & 0.065 & $(0.291)$ & Nonfarm payrolls & $-0.246^{* *}$ & $(-2.485)$ \\
Unemployment & -0.043 & $(-0.584)$ & Industrial production & $-0.212^{*}$ & $(-1.348)$ \\
Ifo Business Climate & $0.857^{* *}$ & $(2.304)$ & Advance GDP & $-0.616^{* *}$ & $(-2.427)$ \\
Industrial production & 0.046 & $(0.664)$ & Consumer confidence & $-0.652 * *$ & $(-2.254)$ \\
Manufacturing orders & 0.053 & $(0.836)$ & Retail sales & -0.133 & $(-0.995)$ \\
Retail Sales & 0.098 & $(1.321)$ & CPI & $0.198^{*}$ & $(1.561)$ \\
PPI & 0.091 & $(1.102)$ & Unemployment rate & $1.703^{* * *}$ & $(2.848)$ \\
GDP & 0.112 & $(0.461)$ & Housing starts & 0.009 & $(0.038)$ \\
Trade Balance & 0.010 & $(0.086)$ & PPI & 0.041 & $(0.472)$ \\
Business confidence & 1.028 & $(1.391)$ & Trade balance & -0.348 & $(-1.133)$ \\
& & & Average workweek & $-0.338 *$ & $(-1.597)$ \\
\end{tabular}

Notes:

${ }^{*, * *},{ }^{* * *}$ denotes significance at the $90 \%, 95 \%, 99 \%$ levels, respectively. Numbers in brackets are t-statistics. 
Table 6: The effect of announcement timing on the magnitude and the significance of exchange rate reactions

\begin{tabular}{l|lr|cr}
\hline \hline & \multicolumn{2}{|c|}{ Coefficients } & \multicolumn{2}{c}{ T-statistics } \\
\hline Constant & $0.000 * * *$ & $(-3.583)$ & $1.764 * * *$ & $(5.930)$ \\
$\beta$ & 0.000 & $(-1.539)$ & $-0.019 *$ & $(-1.983)$ \\
$\mathrm{R}^{2}$ & 0.101 & & 0.158 & \\
\hline \hline
\end{tabular}

Notes:

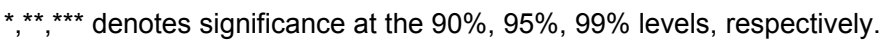

Numbers in brackets are t-statistics. 


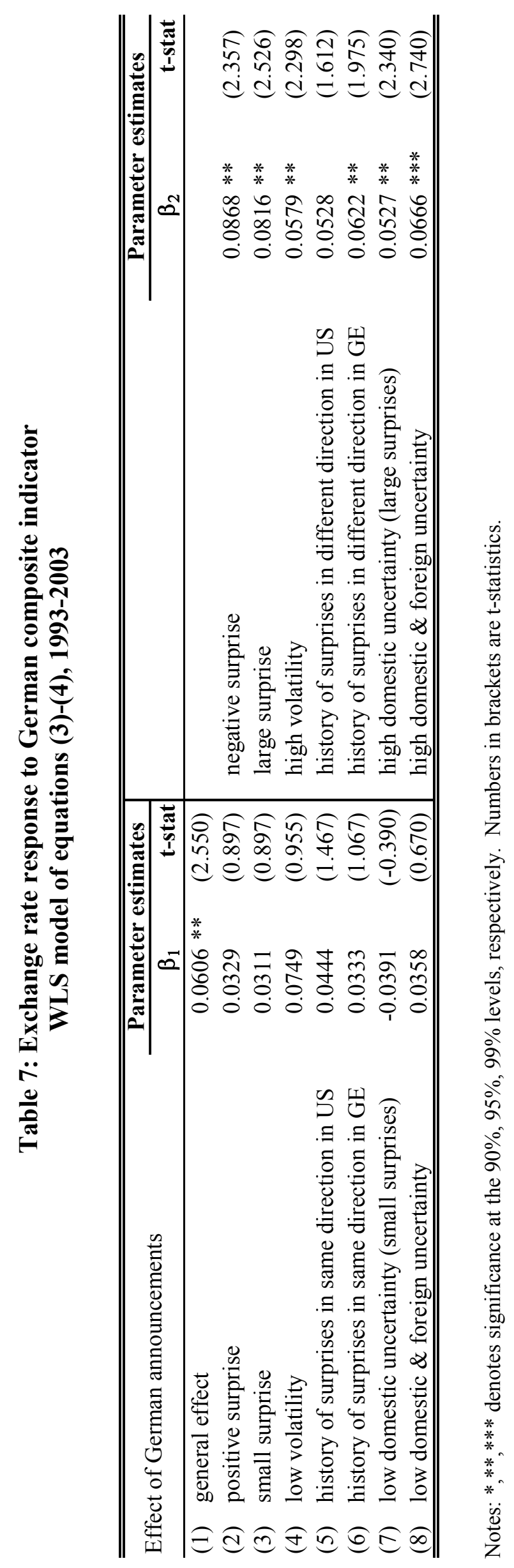




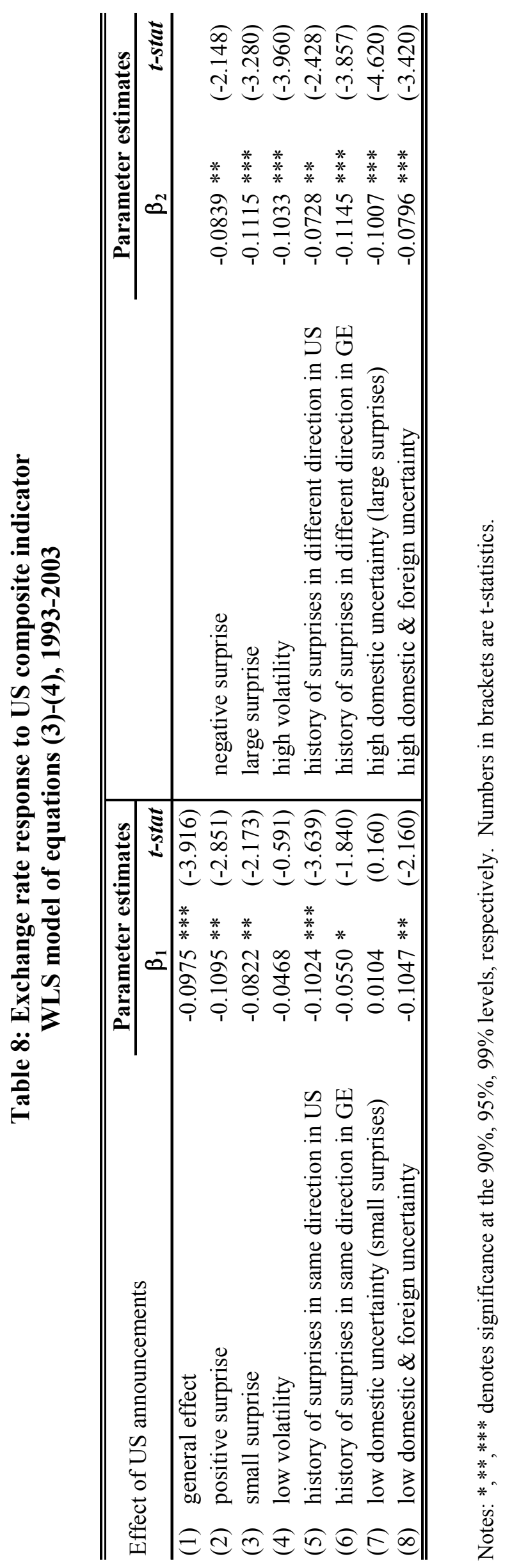


Table 9: Goodness of fit: vintage data versus real-time data

\begin{tabular}{lccccc}
\hline & \multicolumn{3}{c}{ VINTAGE DATA } & REAL-TIME DATA \\
EUR/USD & $\begin{array}{c}\text { average } \\
\text { absolute } \\
\text { exchange rate } \\
\text { (monthly data) }\end{array}$ & $\begin{array}{c}\text { absolute } \\
\text { estimated } \\
\text { actual change }\end{array}$ & $\begin{array}{c}\text { correct } \\
\text { change } \\
\text { explanation }\end{array}$ & $\begin{array}{c}\text { absolute } \\
\text { estimated } \\
\text { change }\end{array}$ & $\begin{array}{c}\text { correct } \\
\text { directional } \\
\text { explanation }\end{array}$ \\
\hline $1993-2003$ & $1.69 \%$ & $0.77 \%$ & $60.71 \%$ & $0.64 \%$ & $73.21 \%$ \\
$1999-2003$ & $1.87 \%$ & $0.84 \%$ & $58.54 \%$ & $0.81 \%$ & $73.17 \%$ \\
\hline
\end{tabular}

Note:

"Average absolute estimated change" shows the average implied monthly exchange rate change based on US and German/euro area macroeconomic fundamentals and their implied parameter estimates.

"Correct directional explanation" indicates the percentage of monthly directional changes that are correctly explained by changes in the macroeconomic fundamentals. 

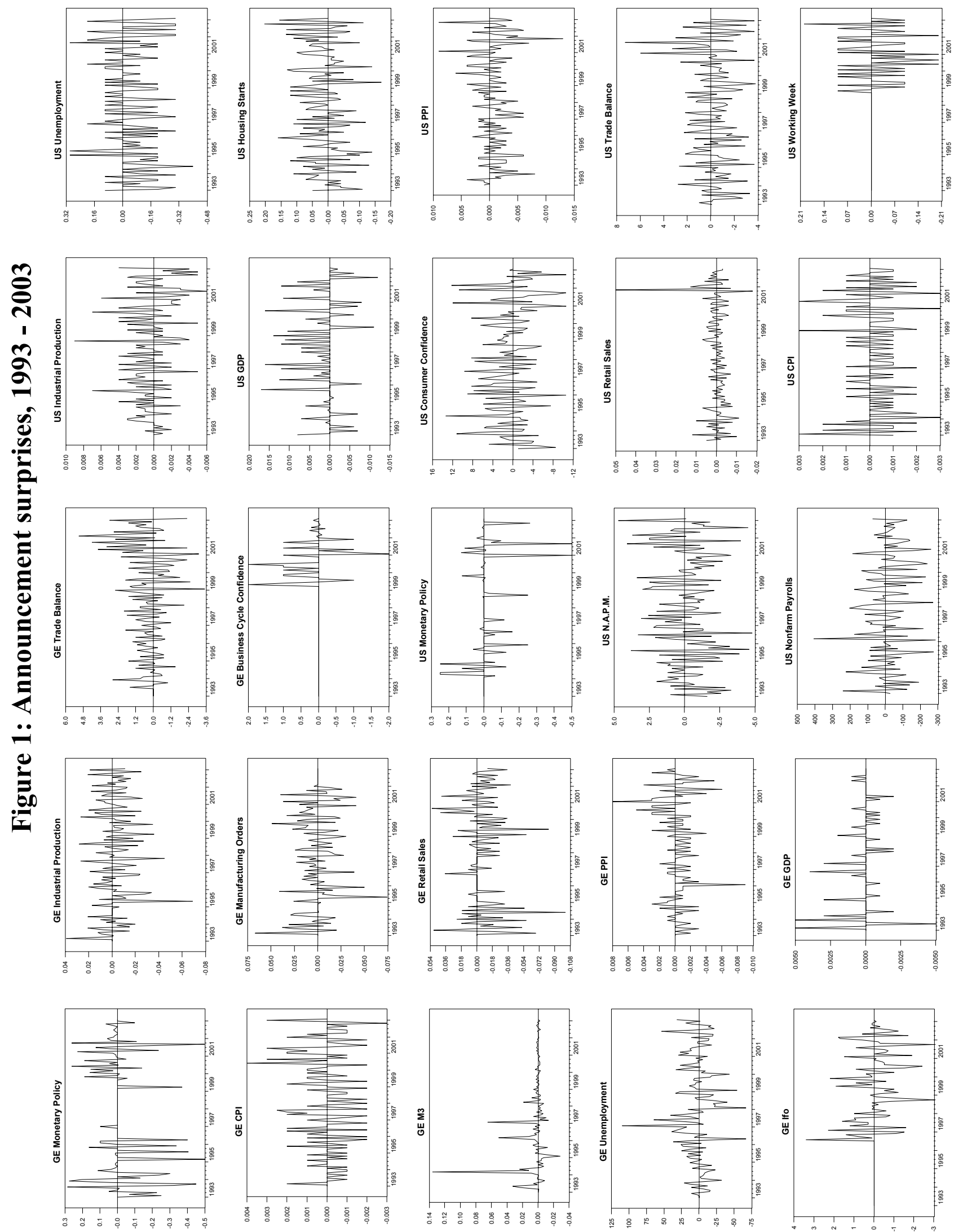
Figure 2: Distribution of release days of macroeconomic announcements

\section{US Macroeconomic Announcement Dates}

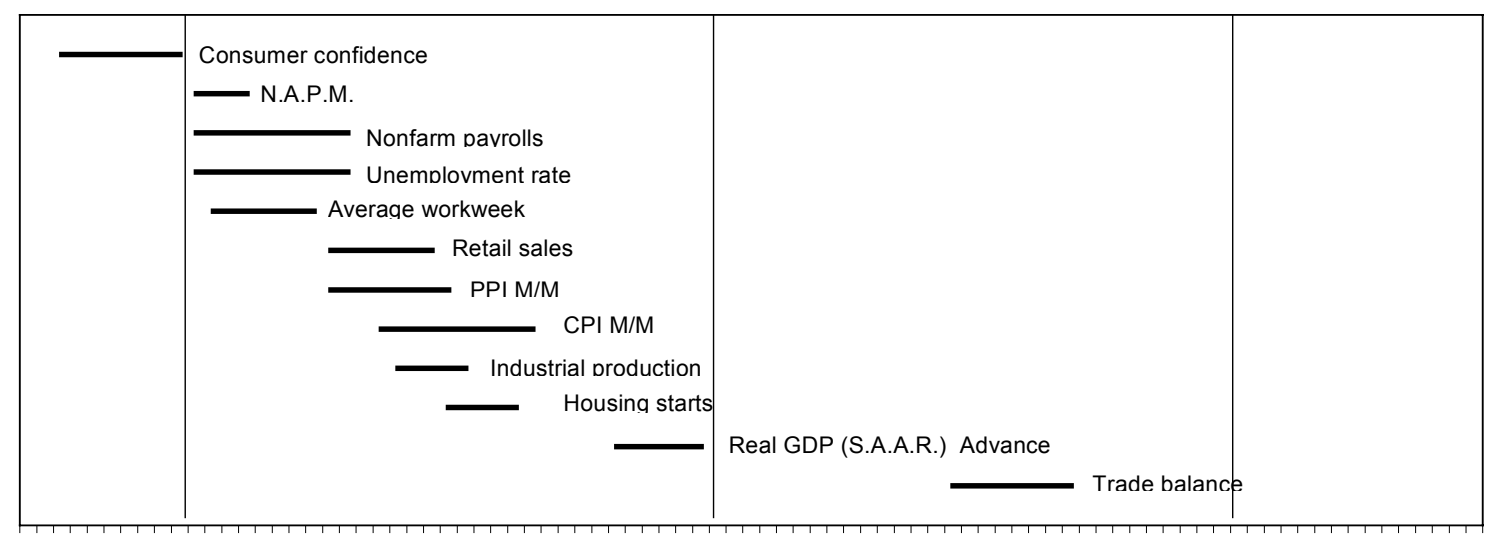

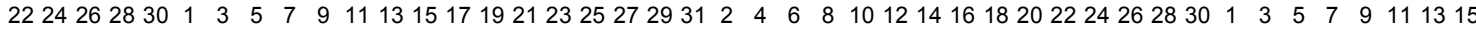
Month $\mathrm{T}=0$

Month $\mathrm{T}+1$

Month $\mathrm{T}+2$

Month $\mathrm{T}+3$

\section{German Macroeconomic Announcement Dates}

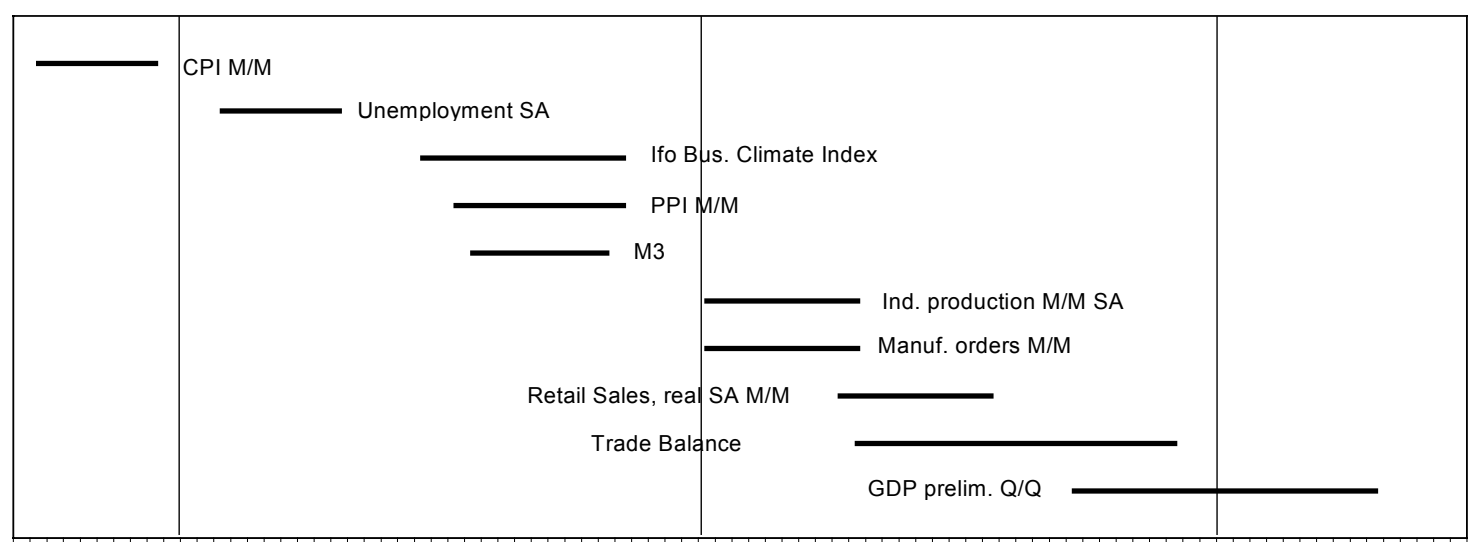

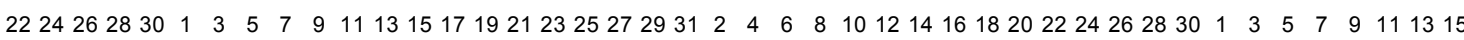

Month $\mathrm{T}=0$

Month T+1

Month T + 2

Month $\mathrm{T}+3$ 


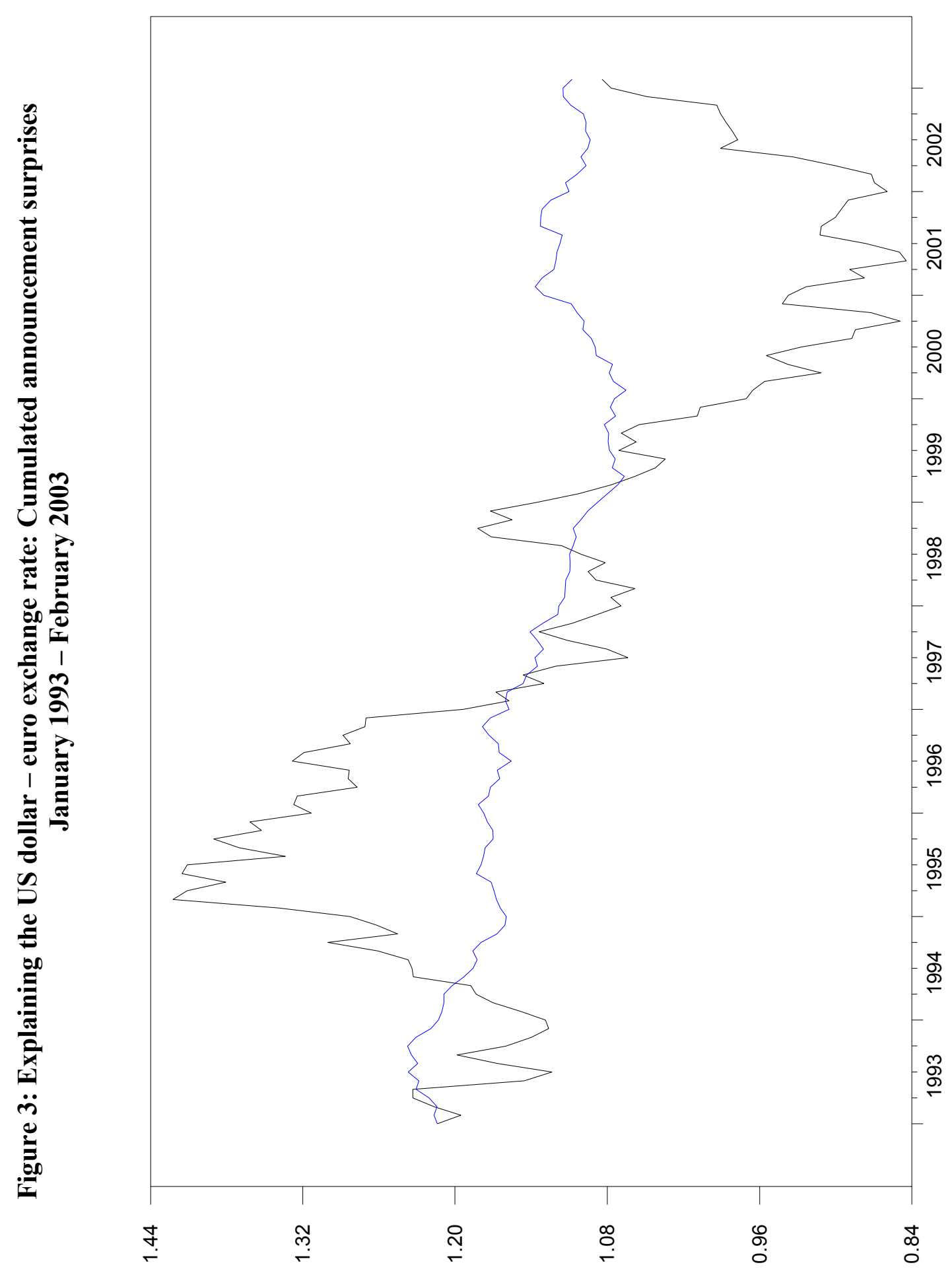




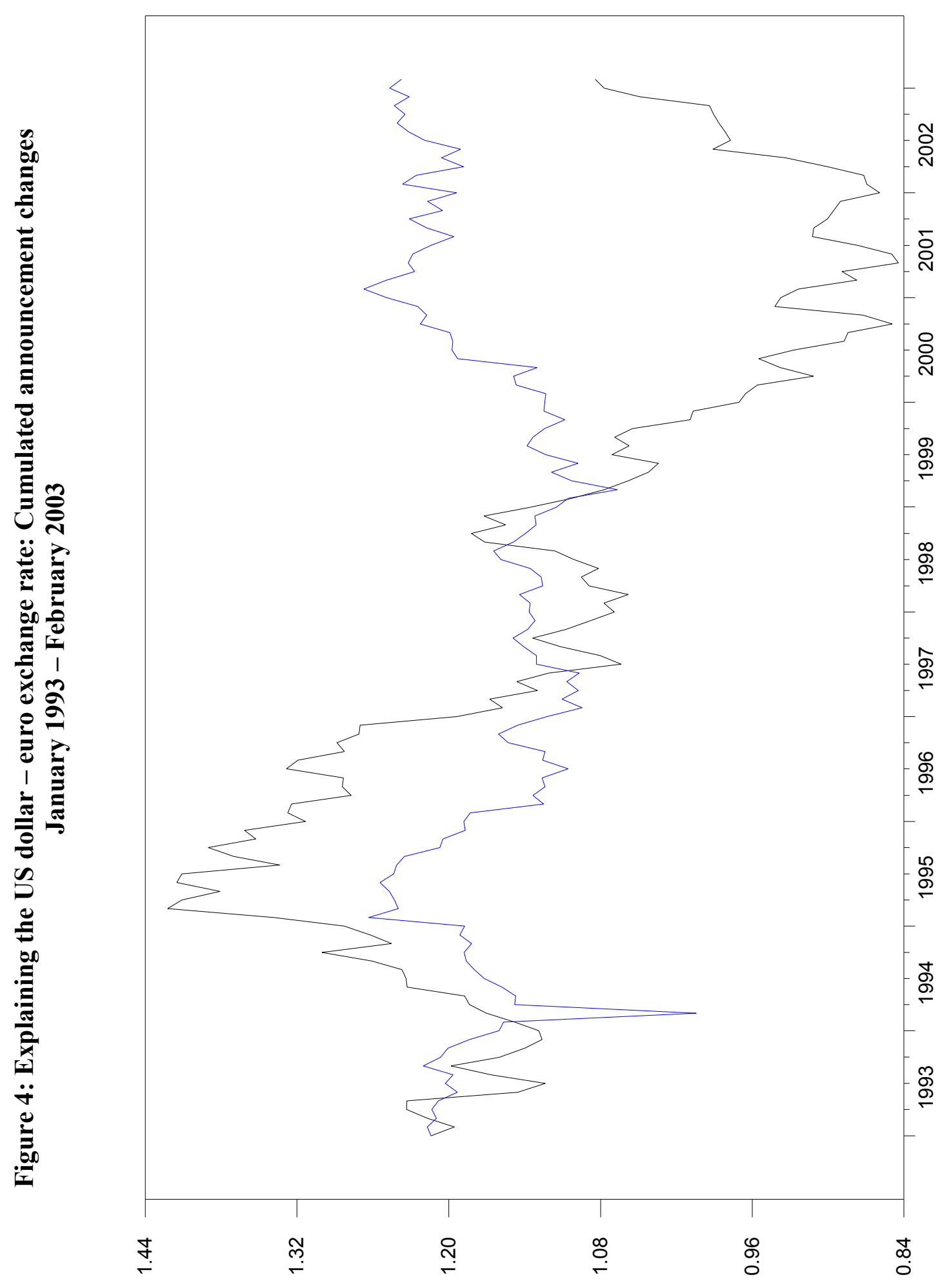




\section{European Central Bank working paper series}

For a complete list of Working Papers published by the ECB, please visit the ECB's website (http://www.ecb.int).

302 "Deposit insurance, moral hazard and market monitoring” by R. Gropp and J. Vesala, February 2004.

303 "Fiscal policy events and interest rate swap spreads: evidence from the EU" by A. Afonso and R. Strauch, February 2004.

304 "Equilibrium unemployment, job flows and inflation dynamics" by A. Trigari, February 2004.

305 "A structural common factor approach to core inflation estimation and forecasting" by C. Morana, February 2004.

306 "A markup model of inflation for the euro area” by C. Bowdler and E. S. Jansen, February 2004.

307 "Budgetary forecasts in Europe - the track record of stability and convergence programmes" by R. Strauch, M. Hallerberg and J. von Hagen, February 2004.

308 "International risk-sharing and the transmission of productivity shocks" by G. Corsetti, L. Dedola and S. Leduc, February 2004.

309 "Monetary policy shocks in the euro area and global liquidity spillovers" by J. Sousa and A. Zaghini, February 2004.

310 "International equity flows and returns: A quantitative equilibrium approach" by R. Albuquerque, G. H. Bauer and M. Schneider, February 2004.

311 "Current account dynamics in OECD and EU acceding countries - an intertemporal approach" by M. Bussière, M. Fratzscher and G. Müller, February 2004.

312 "Similarities and convergence in G-7 cycles" by F. Canova, M. Ciccarelli and E. Ortega, February 2004.

313 "The high-yield segment of the corporate bond market: a diffusion modelling approach for the United States, the United Kingdom and the euro area" by G. de Bondt and D. Marqués, February 2004.

314 "Exchange rate risks and asset prices in a small open economy" by A. Derviz, March 2004.

315 "Option-implied asymmetries in bond market expectations around monetary policy actions of the ECB" by S. Vähämaa, March 2004. 
316 "Cooperation in international banking supervision" by C. Holthausen and T. Rønde, March 2004.

317 “Fiscal policy and inflation volatility" by P. C. Rother, March 2004.

318 "Gross job flows and institutions in Europe” by R. Gómez-Salvador, J. Messina and G. Vallanti, March 2004.

319 "Risk sharing through financial markets with endogenous enforcement of trades” by T. V. Köppl, March 2004.

320 "Institutions and service employment: a panel study for OECD countries" by J. Messina, March 2004.

321 "Frequency domain principal components estimation of fractionally cointegrated processes" by C. Morana, March 2004.

322 "Modelling inflation in the euro area" by E. S. Jansen, March 2004.

323 “On the indeterminacy of New-Keynesian economics” by A. Beyer and R. E. A. Farmer, March 2004.

324 "Fundamentals and joint currency crises" by P. Hartmann, S. Straetmans and C. G. de Vries, March 2004.

325 "What are the spill-overs from fiscal shocks in Europe? An empirical analysis" by M. Giuliodori and R. Beetsma, March 2004.

326 "The great depression and the Friedman-Schwartz hypothesis" by L. Christiano, R. Motto and M. Rostagno, March 2004.

327 "Diversification in euro area stock markets: country versus industry” by G. A. Moerman, April 2004.

328 "Non-fundamental exchange rate volatility and welfare" by R. Straub and I. Tchakarov, April 2004.

329 “On the determinants of euro area FDI to the United States: the knowledge-capital-Tobin's Q framework, by R. A. De Santis, R. Anderton and A. Hijzen, April 2004.

330 "The demand for euro area currencies: past, present and future" by B. Fischer, P. Köhler and F. Seitz, April 2004.

33I "How frequently do prices change? evidence based on the micro data underlying the Belgian CPI" by L. Aucremanne and E. Dhyne, April 2004.

332 "Stylised features of price setting behaviour in Portugal: 1992-200I" by M. Dias, D. Dias and P. D. Neves, April 2004.

333 "The pricing behaviour of Italian firms: New survey evidence on price stickiness" by S. Fabiani, A. Gattulli and R. Sabbatini, April 2004.

334 "Is inflation persistence intrinsic in industrial economies?" by A. T. Levin and J. M. Piger, April 2004.

335 “Has eura-area inflation persistence changed over time?" by G. O'Reilly and K. Whelan, April 2004.

336 "The great inflation of the 1970s" by F. Collard and H. Dellas, April 2004.

337 "The decline of activist stabilization policy: Natural rate misperceptions, learning and expectations" by A. Orphanides and J. C. Williams, April 2004. 
338 "The optimal degree of discretion in monetary policy" by S. Athey, A. Atkeson and P. J. Kehoe, April 2004.

339 "Understanding the effects of government spending on consumption" by J. Galí, J. D. López-Salido and J. Vallés, April 2004.

340 "Indeterminacy with inflation-forecast-based rules in a two-bloc model" by N. Batini, P.Levine and J. PearIman, April 2004.

34I "Benefits and spillovers of greater competition in Europe: A macroeconomic assessment" by T. Bayoumi, D. Laxton and P. Pesenti, April 2004.

342 "Equal size, equal role? Interest rate interdependence between the euro area and the United States" by M. Ehrmann and M. Fratzscher, April 2004.

343 "Monetary discretion, pricing complementarity and dynamic multiple equilibria" by R. G. King and A. L. Wolman, April 2004.

344 "Ramsey monetary policy and international relative prices" by E. Faia and T. Monacelli, April 2004.

345 “Optimal monetary and fiscal policy: A linear-quadratic approach" by P. Benigno and M. Woodford, April 2004.

346 "Perpetual youth and endogenous labour supply: a problem and a possible solution" by G. Ascari and N. Rankin, April 2004.

347 "Firms' investment decisions in response to demand and price uncertainty" by C. Fuss and P. Vermeulen, April 2004.

348 "Financial openness and growth: Short-run gain, long-run pain?" by M. Fratzscher and M. Bussiere, April 2004.

349 "Estimating the rank of the spectral density matrix" by G. Camba-Mendez and G. Kapetanios, April 2004.

350 "Exchange-rate policy and the zero bound on nominal interest rates" by G. Camba-Mendez and G. Kapetanios, April 2004.

35 I "Interest rate determination in the interbank market" by V. Gaspar, G. P. Quirós and H. R. Mendizábal, April 2004.

352 "Forecasting inflation with thick models and neural networks" by P. McNelis and P. McAdam, April 2004.

353 "Towards the estimation of equilibrium exchange rates for CEE acceding countries: methodological issues and a panel cointegration perspective" by F. Maeso-Fernandez, C. Osbat and B. Schnatz, April 2004.

354 "Taking stock: monetary policy transmission to equity markets" by M. Ehrmann and M. Fratzscher, May 2004.

355 "Production interdependence and welfare" by K. X. D. Huang and Z. Liu, May 2004. 
356 "Developing a euro area accounting matrix: issues and applications" by T. Jellema, S. Keuning, P. McAdam and R. Mink, May 2004.

357 "Seasonal adjustment and the detection of business cycle phases" by A. M. Mir and D. R. Osborn, May 2004.

358 "Did the pattern of aggregate employment growth change in the euro area in the late 1990s?" by G. Mourre, May 2004.

359 "The longer term refinancing operations of the ECB" by T. Linzert, D. Nautz and U. Bindseil, May 2004.

360 "Optimal monetary policy rules for the euro area: an analysis using the area wide model" by A. Dieppe, K. Küster and P. McAdam, May 2004.

$36 \mathrm{I}$ "Excess reserves and the implementation of monetary policy of the ECB" by $U$. Bindseil, G. Camba-Mendez, A. Hirsch and B. Weller, May 2004.

362 "Oil price shocks and real GDP growth: empirical evidence for some OECD countries" by R. Jiménez-Rodríguez and M. Sánchez, May 2004.

363 "Communication and exchange rate policy" by M. Fratzscher, May 2004.

364 “Asset price booms and monetary policy” by C. Detken and F. Smets, May 2004.

365 "Exchange rates and fundamentals: new evidence from real-time data" by M. Ehrmann and M. Fratzscher, May 2004. 
